\title{
O Curso Técnico em Cooperativismo realizado pelo PRONERA: uma análise baseada na Abordagem das Capacitações
}

\author{
Conceição Coutinho Melo ${ }^{1}$, Paulo Dabdab Waquil ${ }^{2}$ \\ ${ }^{1}$ Instituto Nacional de Colonização e Reforma Agrária - INCRA. Coordenação Geral de Educação do Campo e \\ Cidadania - DDE. SBN Quadra 1 Bloco D. Ed. Palácio do Desenvolvimento. Brasília - DF. Brasil. \\ ceicao4@yahoo.com.br ${ }^{2}$ Universidade Federal do Rio Grande do Sul - UFRGS.
}

\begin{abstract}
RESUMO. Este artigo apresenta resultados de uma pesquisa sobre o Curso Técnico em Cooperativismo (TAC), que surge na década de 90 como demanda do MST em formar técnicos para atuar nas cooperativas dos assentamentos rurais de Reforma Agrária. Atualmente o curso é realizado através do Programa Nacional de Educação na Reforma Agrária - PRONERA, sob o paradigma da Educação do Campo. A Educação do Campo é aqui compreendida como um dos alicerces para o desenvolvimento rural, sob um prisma multidimensional. Diante disso, buscou-se um desafiador diálogo entre Economia e Educação do Campo, contribuindo na discussão sobre um campo empírico ainda não explorado sob a égide da Abordagem das Capacitações. Esta abordagem, desenvolvida pelo indiano Amartya Sen, discute o desenvolvimento como expansão das capacitações das pessoas para viver a vida que almejam, onde a renda monetária não é o primordial para o bem-estar, mas outras variáveis (educação, saúde, liberdade política, etc.). Pretendeuse investigar se o curso TAC contribui para a expansão das capacitações de seus egressos e para o desenvolvimento dos assentamentos rurais. Todos os entrevistados continuaram seus estudos e atuaram, depois de formados, em entidades ligadas aos assentamentos. $\mathrm{O}$ processo formativo do TAC tem contribuído na expansão da liberdade dos egressos.
\end{abstract}

Palavras-chave: Educação do Campo, PRONERA, Abordagem das Capacitações. 


\title{
The Technical Course in Cooperatives by PRONERA: an analysis based on the People's Capabilities Approach
}

\begin{abstract}
This paper presents results from a research about the Cooperatives Thechnical Course (TAC), originated in the 90's after a need of the MST for forming technical staff for working in cooperatives located in rural settlements as part of the Land Reform. Nowadays, the course is taught through the National Program of Education within the Land Reform (PRONERA), under the paradigm of Rural Education. Rural Education is understood as one of the motivations for the rural development, from a multidimensional viewpoint. Therefore, a challenging dialogue between Economy and Rural Education emerged, and contributed to a field little explored under the aegis of the People's Capabilities Approach. In such approach, developed by the Indian Amartya Sen, development is seen as people's capabilities expansion for living the lives they yearn, where monetary income is not essential for the well-being, but other variables (education, health, political liberty, etc.). The goal in this research was to investigate if the TAC contributes to the expansion of capabilities of its graduates and to the development of rural settlements. All the people interviewed graduated, and after that, worked in entities related to rural settlements. The TAC has contributed to the graduates' liberty expansion.
\end{abstract}

Keywords: Rural Education, PRONERA, People's Capabilities Approach. 


\section{El Curso Técnico en Cooperativismo realizado de PRONERA: un análisis basado en el Abordaje de Capacidades}

RESUMEN. Este artículo presenta resultados de una investigación sobre el Curso Técnico en Cooperativismo (TAC), surgido en los años 90 como demanda del MST de formar técnicos para cooperativas de asentamientos rurales de la Reforma Agraria. Actualmente, el curso es realizado a través del Programa Nacional de Educación en la Reforma Agraria (PRONERA), bajo el paradigma de Educación Rural. La Educación Rural es comprendida aquí como uno de los alicientes para el desarrollo rural, con enfoque multidimensional. Por tanto, se buscó un diálogo desafiante entre Economía y Educación Rural, contribuyendo a la discusión sobre un campo empírico todavía no explorado bajo la guía del Abordaje de Capacidades. Este abordaje, desarrollado por el hindú Amartya Sen, discute el desarrollo como expansión de las capacidades de las personas para vivir la vida que anhelan, no siendo primordial el ingreso monetario para el bienestar, sino otras variables (educación, salud, libertad política, etc.). Se pretendió investigar si el curso TAC contribuye a la expansión de las capacidades de sus graduados y al desarrollo de asentamientos rurales. Todos los entrevistados continuaron sus estudios y actuaron, al graduarse, en entidades ligadas a asentamientos. El TAC ha contribuido a la expansión de la libertad de los egresados.

Palabras clave: Educación Rural, PRONERA, Abordaje de Capacidades. 


\section{Introdução}

O objetivo principal desta pesquisa foi investigar se o curso Técnico em Cooperativismo (TAC), realizado através do Programa Nacional de Educação na Reforma Agrária (PRONERA), interfere na realização de funcionamentos e expansão das capacitações de seus egressos.

Para alcançar este objetivo foram delineados três objetivos específicos: a) caracterizar o perfil e a trajetória dos egressos antes e depois de formados no TAC; b) identificar se o TAC pode ser considerado um instrumento de expansão das capacidades dos egressos; e c) conhecer a análise coletiva que se faz sobre o resultado do curso TAC, como instrumento de expansão de capacidades dos egressos, para o desenvolvimento dos assentamentos, sob o ponto de vista dos representantes da Cooperativa Central dos Assentamentos do RS (COCEARGS).

Conhecer qualitativamente os resultados deste curso técnico, utilizandose de dados quantitativos e de uma abordagem teórica ainda não utilizada para este campo empírico, tornou-se um desafio que se pretendeu alcançar a partir do seguinte problema de pesquisa: o curso Técnico em Cooperativismo (TAC) realizado pelo PRONERA no Rio Grande do Sul tem contribuído para a expansão das capacitações dos egressos?

Existem muitas vertentes teóricas que se baseiam na geração de renda como variável imprescindível ao desenvolvimento. Estas abordagens não dariam conta, portanto, da complexidade do assunto tratado neste trabalho. Resolveu-se, pois, lançar mão de uma abordagem multidimensional na qual $\mathrm{o}$ desenvolvimento fosse analisado para além da geração de renda, incluindo o debate acerca da justiça social e que o paradigma da Educação do Campo pudesse ser considerado parte integrante do desenvolvimento rural.

Dessa forma, a perspectiva que mais se adequou a este trabalho foi a Abordagem das Capacitações - ou Abordagem das Capacidades, a depender da tradução. Portanto, no referencial teórico utilizado, lançou-se mão de um audacioso diálogo entre esta Abordagem e os paradigmas da Educação do Campo.

Foi realizado um trabalho de campo em nível nacional, visto que o curso analisado recepciona estudantes de todo o país, de forma que houvesse em cada região, pelo menos uma entrevista, na tentativa de apreender parte da diversidade brasileira, cujos dados, posteriormente, demonstraram as diferentes realidades encontradas, as quais interferem 
diretamente na expansão das capacitações dos egressos.

Esta pesquisa, também pôde proporcionar às entidades executoras do curso TAC um banco de dados digital de todos os egressos, com informações a respeito do perfil de cada um - origem, sexo, idade - como também 30 mapas e 54 gráficos dos ingressantes, desistentes/reprovados e dos próprios egressos. Para além da discussão acadêmica que esta pesquisa proporcionou, essa contribuição para as entidades foi um importante resultado, para os pesquisadores de modo geral que porventura se interessem pela temática, cujas informações a partir desse trabalho, já encontrarão sistematizadas.

O curso TAC, para além do que se pretendia investigar, apresentou variáveis que ultrapassam os resultados esperados de um curso técnico. Além da capacitação profissional, a maior parte dos egressos entrevistados relatou que teve uma formação humana que contribui até os dias atuais na sua vida, como também nas dinâmicas dos assentamentos rurais de Reforma Agrária.

\section{Abordagem das Capacitações e Educação do Campo: um diálogo possível} Abordagem das Capacitações
A Abordagem das Capacitações foi desenvolvida por Amartya Kumar Sen a partir de um diálogo, em muitos aspectos, com a filósofa Marta Nussbaum. Amartya Sen é filósofo e economista indiano cujas contribuições teóricas serviram de base para a criação do Índice de Desenvolvimento Humano (IDH). Em 1998, ganhou o Nobel de Economia, por suas contribuições à economia do bemestar. Seus trabalhos versam, prioritariamente, sobre desenvolvimento, desigualdade e justiça.

Apesar de inúmeros trabalhos já publicados, ainda é um desafio à tentativa de operacionalização da Abordagem das Capacitações. Alguns trabalhos realizados por pesquisadores da Universidade Federal do Rio Grande do Sul (UFRGS) sobre desenvolvimento rural têm sido referenciais importantes de operacionalização da abordagem seniana, dentre os quais destacam-se no referencial teórico deste trabalho Kuhn (2004) e Mattos (2006), os quais contribuem significativamente para auxiliar na interpretação das ideias de Amartya Sen.

Crítico da abordagem utilitarista, Sen (2010) propõe uma nova forma de considerar os elementos constituintes da análise do bem-estar. $\mathrm{O}$ autor afirma que a renda passa a ser um meio de realizações, e não o fim em si do desenvolvimento. Por 
esta razão, o Produto Nacional Bruto (PNB) de um país, ou até mesmo o Produto Interno Bruto (PIB) per capita, não reflete a realidade de desenvolvimento do mesmo. Isto porque outras questões podem ser mais relevantes que a renda per capita, em uma análise avaliatória de desenvolvimento humano. Ele sugere, pois, que outras variáveis devam ser ponderadas na base informacional, como, por exemplo, idade, estado de saúde, escolaridade, clima social, etc. (Sen, 2010).

Para Sen (2010), a parte central do processo de desenvolvimento é a superação de privações de liberdades, que não significa apenas tornar a vida mais rica, mas tornar as pessoas seres sociais mais completos, interagindo e influenciando o mundo, exercendo sua condição de agente. Para os indivíduos exercerem esta condição, as privações de liberdade deverão ser eliminadas, e somente dessa forma os indivíduos teriam escolhas e oportunidades.

Algumas abordagens identificam o desenvolvimento como o crescimento do PNB; PIB; aumento de rendas individuais; industrialização; avanço tecnológico, etc. $\mathrm{Na}$ Abordagem das Capacitações, estes são os meios de expandir as liberdades, às quais também dependem de outros determinantes, como disposições sociais e econômicas e direitos civis. A liberdade é o fim e o meio do desenvolvimento; este é o objetivo em que, consoante Sen (2010), devemos nos concentrar, e não apenas nos meios.

$\mathrm{Na}$ Abordagem das Capacitações, a concepção de desenvolvimento, portanto, consiste na eliminação de privações de liberdade que limitam as escolhas e oportunidades das pessoas exercerem sua condição de agentes.

Para um melhor entendimento deste ponto nevrálgico da abordagem em questão, sugere-se a leitura do trabalho de Kuhn (2004), o qual pontua o seguinte:

Nesse sentido, percebe-se uma concepção de desenvolvimento baseada na forma de vida que a pessoa tem e se ela teve ou não opção de levar a vida que leva. Para além de informações objetivas, Sen indica a necessidade de perceber a avaliação que o agente tem de sua própria condição. É preciso identificar se a pessoa valoriza sua vida e as opções que tem (ou ainda, se valoriza as opções que não pode ter ou se desconhece as opções disponíveis a outras pessoas). Diversos tipos de privações, encontradas tanto nos países ricos como nos países pobres, passam agora a incorporar uma noção de desenvolvimento que vai além da percepção da renda monetária. Sen aposta na análise de condições de vida e das oportunidades dos agentes para conscientizarem-se e exercerem sua "condição de agência". É preciso perceber se, além das condições materiais de vida, as pessoas têm acesso a oportunidades que permitem que elas possam melhorar sua qualidade de vida. (Kuhn, 2004, p. 37-38). 
A Abordagem das Capacitações procura avaliar a liberdade de escolha. Além do princípio da liberdade, outros dois componentes fundamentais dessa abordagem precisam ser esclarecidos: funcionamentos (functionings) e capacitações (capabilities).

Os funcionamentos são os elementos constitutivos do "estado" da pessoa. São o "ser" (being) e o "fazer" (doing) do ser humano. Em outras palavras, são as várias coisas que o indivíduo pode ser e fazer.

Para contribuir com a interpretação da concepção de Capacitações (capabilities), faz-se aqui referência ao trabalho de Mattos (2006), o qual explica que as Capacitações são funcionamentos alternativos, ou seja, são estados ainda não executados efetivamente pela pessoa, mas que são passíveis disto e tornam-se funcionamento por meio de um processo de escolha. Ainda sobre este assunto, Mattos(2006) acrescenta o que segue:

O conjunto capacitário (capability ou capability set) é o conjunto de todas as capacitações. Logo, o conjunto de possibilidades que a pessoa tem para levar a vida que deseja. Este conjunto está revelando, em última análise, a liberdade da pessoa em escolher a vida que deseja levar (Mattos, 2006, p. 40).

Com base na perspectiva seniana, capacitação é um tipo de liberdade que permite realizar combinações alternativas de funcionamentos. Estes consistem em uma diversidade de coisas que uma pessoa pode considerar importante fazer ou ter. Isto não se resume à ideia de renda, pois esta é diferente de capacitação, visto que, a depender da idade, estado de saúde, etc., pode-se necessitar de mais renda para obter os mesmos funcionamentos.

Em contraste com as linhas de pensamento baseadas na utilidade ou nos recursos, na abordagem das capacidades a vantagem individual é julgada pela capacidade de uma pessoa para fazer coisas que ela tem razão para valorizar. Com relação às oportunidades, a vantagem de uma pessoa é considerada menor que a de outra se ela tem menos capacidade menor oportunidade real - para realizar as coisas que tem razão para valorizar. $\mathrm{O}$ foco aqui é a liberdade que uma pessoa realmente tem para fazer isso ou ser aquilo - coisas que ela pode valorizar fazer ou ser (Sen, 2011, p. 265-266).

A expansão da liberdade, segundo a Abordagem das Capacitações, é vista como o principal fim e meio do desenvolvimento. Adotar a visão deste como liberdade é compreender o processo de inter-relações entre as diferentes liberdades e disposições institucionais, que proporcionam oportunidades sociais. Estas oportunidades geram liberdades, que por sua vez influenciam as oportunidades: “... oportunidades sociais de educação e assistência médica, que podem requerer a ação pública, complementam 
oportunidades individuais de participação econômica e política e também favorecem nossas iniciativas para vencer privações" (Sen, 2010, p. 10).

\section{Educação do Campo}

Em que pese à construção da dicotomia campo-cidade (gerada pelo fato de os contextos político e socioeconômico da realidade brasileira estarem sendo cada vez mais permeados pelas relações atuais entre as cidades e o campo), ainda assim consideramos que o legado histórico necessita de políticas específicas, principalmente na área da educação.

A complexidade das condições socioeconômicas e educacionais das populações rurais exige maior coerência na construção de estratégias que visem alavancar a qualidade da Educação do Campo. Desenhar políticas que busquem suprir as enormes desigualdades no direito ao acesso e a permanência na escola para este grupo faz parte desta estratégia, dito de outra forma: o que se busca não é somente a igualdade de acesso 'tolerada' pelos liberais, mas fundamentalmente a igualdade de resultados (Molina, 2008, p. 28).

Fernandes e Molina (2004) fazem menção à "superioridade" atribuída ao espaço urbano, que mascarou as consequências do modelo de desenvolvimento agrícola das últimas décadas, associando aos camponeses, indígenas e quilombolas a imagem de grupos inferiores da sociedade, ocasionando, pois, a negação de direitos. Portanto, a materialização do direito à Educação do Campo configura-se como importante instrumento com potencial aliado a outras políticas sociais - para diminuir as desigualdades e de expansão das capacidades dos indivíduos para fazerem o que desejam. "É a compreensão da ideia do direito a ter direitos que fundamenta a ação dos movimentos sociais como demandantes do que está previsto na lei, mas não materializado na realidade social" (Molina, 2008, p. 23).

Considerando a educação como uma das prioridades no meio rural, frente às históricas injustiças ocasionadas pela dicotomia entre campo e cidade, as possibilidades concretas de realização de justiça social nessa dimensão perpassam pela discussão acerca de políticas de redistribuição e reconhecimento.

Os povos do campo ${ }^{\mathrm{i}}$, diante desse legado têm sido tolhidos de muitas liberdades que contribuem para seu bemestar. Como consequência, estão em desvantagem diante das escolhas do modo de vida. No âmbito educacional, principalmente pela privação de acesso a escolas ou de ensino adequado à realidade rural, esses povos encontram-se diante de possibilidades reais muito distintas da população urbana. 
Essa desigualdade precisa ser reparada, de modo que a população das áreas rurais e da cidade possam ter resultados semelhantes. O meio para isso, diante dessas diferenças, também deverá ser diferenciado. Isto justifica, por exemplo, a criação, nas Universidades, de turmas especiais - com processo seletivo e metodologias próprias - de graduação para o público da Reforma Agrária.

Isso que foi dito relaciona-se com o que Sen (2008) assevera: o que deve ser igualado são as capacitações, as oportunidades para atingir objetivos ligados ao bem-estar - weel-being objectives (Sen, 2008).

A educação é um importante instrumento para diminuir as desigualdades, e a Abordagem das Capacitações contribui para a análise desta área, conforme aponta Picolotto:

O objetivo intrínseco da Abordagem das Capacitações é ver a educação como expansão das capacitações das pessoas e analisar as desigualdades educacionais, conforme Unterhalter (2003), Robeyns (2006), Unterhalter, Vaughan e Walker (2007). A AC também pode ser considerada como uma resposta às limitações das teorias que avaliam educação somente a partir da ótica da satisfação de desejos, recursos ou resultados (2010, p. 2).

As especificidades de grupos sociais demandam um tratamento público para a educação, ou seja, exigem alternativas para assegurar esta prerrogativa. Tomando por base as diversas teorias de justiça social, inclusive a Abordagem das Capacitações, este deveria ser o papel das políticas públicas: atender de forma diferenciada os que possuem necessidades diferenciadas.

No entanto, o atendimento dessas demandas depende, em parte, da forma como são percebidas as desigualdades e os desiguais, pois reflete no modo como o Estado compreende a si mesmo e atua. Os desiguais são vistos principalmente como carentes, marginais, excluídos e inconscientes, e para cada um desses tipos o Estado se enxerga e atua diferentemente, ocultando muitas vezes o problema real da desigualdade, através das visões reducionistas dos coletivos feitos desiguais - coletivos sociais, raciais, do campo, etc. (Arroyo, 2010).

Contudo, nas políticas educacionais públicas do ensino básico e processos avaliatórios, as desigualdades construídas historicamente muitas vezes são desconsideradas, e o foco recai sobre fatores intraescolares (desigualdades escolares) como, por exemplo, a oferta de turmas noturnas para educandos fora da faixa etária. A responsabilização, por sua vez, é atribuída aos professores e estudantes. Por isso, Arroyo chama atenção para a retomada urgente da relação não superada entre educação e desigualdades 
para repensar o Estado, instituições e políticas. Quando os "coletivos feitos desiguais" se afirmam como sujeitos de direitos de políticas, “... as desigualdades dos coletivos sem-teto, sem-terra, semespaço, sem-comida, sem-universidade, sem-territórios entram na escola como nunca antes e interrogam as políticas educativas, sua gestão e suas análises” (Arroyo, 2010, p. 1384).

Arroyo (2010) ressalta que as desigualdades em abstrato não têm rosto ou lugar, mas os coletivos feitos desiguais têm raça, classe, etnia, gênero e lugar. Portanto, pensar as desigualdades de forma abstrata tem trazido consequências sérias para a formulação de políticas, sua gestão e análises. Ainda segundo o autor, cada vez mais as políticas, nessa perspectiva, centralizam a ação no Estado, com políticas generalistas. Assim, os sujeitos das desigualdades são vistos como passivos de políticas de um Estado benevolente, protetor dos desiguais.

A diferença social torna-se um meio de desigualdade, quando as necessidades específicas de grupos sociais são ignoradas ou tratadas de forma uniforme, desconsiderando-se suas especificidades. $\mathrm{O}$ não reconhecimento, portanto, leva à construção de territórios de cidadania e de não cidadania, conforme Arroyo (2010):
A produção das desigualdades esteve e continua associada a processos de não reconhecimento, de inexistência, de não pertença à comunidade política nem territorial. Como consequência as presenças afirmativas dos outros carregam um profundo significado de pertencimento, de ocupação do espaço público, de espaços urbanos, de terras, territórios, instituições, escolas, universidades, até do Estado. Daí que a entrada na escola e na universidade seja tão importante para os coletivos feitos desiguais, inexistentes, desterritorializados, porque diferentes. Entrar passa a ser um gesto e ritual carregado de significados de existência e de pertença, de disputa e de ocupação de territórios. Significados radicais que dão novos sentidos a dominar $\mathrm{o}$ letramento ou numeramento (Arroyo, 2010, p. 1407).

A institucionalização da educação como direito não foi suficiente por si só para $\mathrm{o}$ atendimento às demandas dos desiguais.

É preciso compreender que os princípios legais da educação são convenções sociais que dão ao Estado as diretrizes e as bases para estabelecer políticas, neste caso, educacionais que visem à conquista dos direitos sociais. Pois, uma criança não escolarizada, não letrada, é a certeza de que o direito à educação, à formação integral, lhe foi negada, retirada, não, apenas de uma pessoa; de uma nação que não se fez igualitária, justa, inclusiva (Garcia, 2008, p. 26-27).

O acesso à educação, neste trabalho definido como intitulamento, foi dificultado, como anteriormente relatado, à 
grande parcela da população rural brasileira, devido ao descaso com a educação rural. A retenção dessa liberdade (liberdade de escolha, na concepção seniana), ou seja, a dificuldade de acesso à educação principalmente no campo significa, em outras palavras, a privação da liberdade de estudar e consequentemente um entrave ao desenvolvimento rural.

A educação como movimento de reestruturação da educação para o campo manifesta-se como uma forma política de redistribuição e reconhecimento às populações rurais enquanto sujeitos de sua própria história, que em muitos casos estão organizados em movimentos sociais.

Os direitos questionam as desigualdades sociais e recolocam o julgamento das questões sociais sob a ótica da igualdade, da diferença e da justiça, por isso, os direitos não estão restritos ao marco legal. $\mathrm{O}$ direito para ser direito não necessariamente precisa ser jurídico, mas deve ser reconhecido como tal. Portanto, os movimentos sociais, requerem sujeitos ativos que tomam para si a definição de seus direitos e buscam seu reconhecimento efetivado (Silva, 2006, p. 85).

Destaca-se aqui a materialização do direito à Educação do Campo a partir da experiência do PRONERA que será abordada de forma mais detalhada a seguir. Esta política tem em seus princípios e objetivos atender às especificidades de populações do campo, que historicamente foram constituidores de coletivos feitos desiguais não apenas no âmbito de diferenças econômicas, mas também na dimensão do não reconhecimento de direitos, como, por exemplo, o direito à educação específica.

\section{PRONERA e o Curso Técnico em Cooperativismo - TAC}

No final dos anos de 1990, o Programa Nacional de Educação na Reforma Agrária - PRONERA surge como uma política social compensatória ${ }^{\text {ii }}$, face ao tensionamento de diversos atores sociais, notadamente o Movimento dos Trabalhadores Rurais Sem Terra (MST), frente ao governo federal, à época do então presidente Fernando Henrique Cardoso, cuja gestão foi marcada pelo recrudescimento do Estado mínimo. Isso ocasionou a forte pressão política em relação ao debate sobre o atendimento às famílias rurais de acampamentos e assentamentos de reforma agrária. Nesse contexto, a educação rural, além de não dar conta da demanda quantitativa, possuía uma metodologia de ensino desconectada da realidade dessas famílias.

Diante da dicotomia campo-cidade gerada pelo histórico político, social e econômico da realidade brasileira, em que pese estar sendo cada vez mais permeável pelas relações atuais entre as cidades e o campo, o rural necessita de políticas específicas, as quais, na década de 1990 e início dos anos 2000, surgem principalmente 
como resposta às reivindicações dos movimentos sociais. (Castro \& Melo, 2014, p. 98).

Nesta conjuntura, o PRONERA teve seu marco político em meados de julho de 1997, quando ocorreu o I Encontro Nacional de Educadoras e Educadores da Reforma Agrária (ENERA), na Universidade de Brasília (UnB). Este evento foi promovido pelos seguintes atores: MST, UnB, Fundo das Nações Unidas para a Infância (UNICEF), Organização das Nações Unidas para a Educação, Ciência e Cultura (UNESCO) e Conferência Nacional dos Bispos do Brasil (CNBB).

Em 1998, em Luziânia (GO), estes mesmos atores sociais promoveram a $1^{\mathrm{a}}$ Conferência Nacional por uma Educação Básica do Campo, e a partir disso deu-se início à Articulação Nacional por uma Educação Básica do Campo, que defende o campo como um espaço de vida digna e a construção de uma educação voltada à realidade concreta das famílias rurais.

Este acúmulo de ações, discussões e articulações, aliado ao apoio da sociedade à reforma agrária, culminou na criação do PRONERA, através da Portaria n ${ }^{\circ} 10$ de 16 de abril de 1998, do Ministério Extraordinário da Política Fundiária, sendo executado pelo Instituto Nacional de Colonização e Reforma Agrária (INCRA).
Nesta Portaria, destaca-se o objetivo do PRONERA de fortalecer a educação nos projetos de assentamentos de reforma agrária, utilizando metodologias específicas para o campo que contribuíssem para o desenvolvimento rural sustentável destes. Este Programa, apesar de ter sido criado em 1998, torna-se reconhecido normativamente como Política Pública somente a partir do Decreto $\mathrm{n}^{\circ}$ 7.352, de 04 de novembro de 2010.

Dentre os cursos formais realizados por meio do PRONERA, destaca-se o Curso Técnico em Cooperativismo. Até o lançamento do novo Catálogo Nacional de Cursos Técnicos de Nível Médio, publicado pelo Ministério da Educação (MEC) em 2008, este curso era denominado Curso Técnico em Administração de Cooperativas, cuja sigla era e permanece sendo, tanto para o PRONERA quanto para o MST, simplesmente "TAC".

O TAC surgiu no município de Braga, no estado do Rio Grande do Sul em 1993, formando jovens e adultos de todo o país, e funcionou com base em um sistema de autogestão, aliando trabalho e estudo. Todavia, em 1999, para a realização de uma turma do TAC (turma 05) foi firmado o primeiro convênio do INCRA/PRONERA com o Instituto Técnico de Capacitação e Pesquisa da 
Reforma Agrária (ITERRA), em Veranópolis/RS. No período compreendido entre 1999 e 2016, foram concluídas 10 turmas do referido curso, todas realizadas no ITERRA por intermédio do PRONERA (Pesquisa Direta, INCRA Sede/PRONERA, out/2017).

Christoffoli (2007), Menezes Neto (2003), Cerioli (1997), etc. apresentam a importância do TAC em razão da sua especificidade metodológica, isto é, do trabalho como elemento pedagógico e sua vinculação direta com o processo produtivo das cooperativas ligadas ao MST.

Atualmente, a duração do TAC é de três anos e meio, incluindo em seu currículo, a partir de 2003, aulas de Planejamento do Desenvolvimento Sustentável dos Assentamentos. Segundo Christoffoli (2007), esta mudança na estrutura curricular se deu para que se pudessem desenvolver metodologias que ajudassem a organizar os assentamentos.

Ademais, é importante ressaltar que, também com o intuito de organizar os assentamentos, foi constituída, em 1991 (apenas dois anos antes do surgimento do curso TAC), a Cooperativa Central dos Assentamentos do Rio Grande do Sul (COCEARGS), com sede na cidade de Porto Alegre.
Esta cooperativa, além de ter como finalidade organizar os assentamentos do estado, também surge com o intuito de representá-los, buscar linhas de crédito, articular assistência técnica e política dos assentados, organizar a produção e a agroindustrialização e incentivar a cooperação. Ligado à criação desta cooperativa central, o MST criou, com o objetivo de estimular e massificar a cooperação agrícola dentro dos assentamentos, a Confederação das Cooperativas da Reforma Agrária (CONCRAB), em 1992, articulando todas as cooperativas em âmbito nacional (Santalucia \& Hegedus, 2005).

Desta forma, o TAC, quando da sua criação, em 1993, esteve estreitamente ligado ao desenvolvimento das discussões e práticas de cooperação dos assentamentos ligados ao MST, e “... surge como demanda do Movimento para a formação de quadros técnicos capazes de dar conta do gerenciamento das organizações associativas que vinham sendo constituídas nos assentamentos ..." (Christoffoli, 2007 p. 71).

Para os assentamentos do Rio Grande do Sul, este curso é estratégico, uma vez que contribui com a organização e o funcionamento das cooperativas centralizadas pela COCEARGS. Porém, existe um questionamento que 
consideramos relevante: qual seria a contribuição deste curso na vida dos egressos?

\section{A Pesquisa de Campo e os principais resultados encontrados}

Na pesquisa exploratória foi possível o acesso a algumas informações das 493 pessoas que ingressaram no TAC (até o período desta pesquisa), das quais 265 eram egressos do curso e 228 foram desistentes/reprovados/transferidos. Dentre este universo, a pesquisa se deteve aos egressos das turmas formadas em parceria entre INCRA, ITERRA e o Instituto de Pesquisa e Educação do Campo (IPECAMPO), no período de 1999 a 2015, totalizando o quantitativo de 265 egressos.

Foram analisadas 493 pastas individuais manualmente - Estas informações estavam dispersas em diversas folhas de papel, dentro de antigas pastas de arquivo suspenso - das quais 265 eram de $\begin{array}{llll}\text { egressos } & \text { e } & 228 & \text { de }\end{array}$ desistentes/reprovados/transferidos. Foram anotadas as informações que serviriam para esta pesquisa: turma, nome completo, sexo, data de nascimento, assentamento/município/estado de origem. Em relação aos desistentes ou reprovados do curso, foram anotados apenas o estado de origem.
$\mathrm{O}$ curso TAC teve quatro turmas formadas anteriormente à criação do PRONERA, porém esta pesquisa se deteve às turmas formadas através deste programa, ou seja, a partir do momento que este curso passa a ser ofertado através de uma política pública, e não apenas pelo MST.

Deste universo escolhido optou-se pesquisar apenas uma amostragem, apesar desta pesquisa possuir cunho qualitativo e utilizar algumas ferramentas do método quantitativo, a escolha de amostragem não objetivou a necessidade de representatividade do universo. A preocupação gira em torno da qualidade das informações, atingindo certo grau de saturação das mesmas. Além disso, para o atingimento dos objetivos desta pesquisa, também os atuais representantes da COCEARGS e da CONCRAB também serviram de unidade de análise.

Inicialmente foi contatada a diretoria do Instituto de Educação Josué de Castro (IEJC), responsável pela administração do curso no ITERRA E IPE CAMPO (as três instituições funcionam no mesmo prédio, localizado no município de Veranópolis/RS), para explicar os objetivos da pesquisa e um dos coordenadores pedagógicos dessa instituição indicou um representante da 
COCEARGS, coincidentemente egresso do TAC, para iniciar o estudo.

A partir de uma conversa inicial com esse diretor, que posteriormente participou da pesquisa enquanto direção da COCEARGS foi-nos apresentado um egresso que atualmente trabalha nesta cooperativa central. Daí em diante, cada pessoa contatada fornecia o número do telefone ou correio eletrônico de alguém que pudesse contribuir para esse trabalho, de modo que esta "rede solidária", no decorrer da pesquisa, nos forneceu diversos contatos, que em sua maioria se disponibilizou a participar, embora nem todos tenham podido, por motivos pessoais ou de logística.

Por fim, a amostragem foi de 22 pessoas: 19 egressos, dois diretores da COCEARGS e um diretor da CONCRAB.

Quadro 1 - Distribuição dos egressos entrevistados por origem.

\begin{tabular}{|c|c|c|}
\hline Região & Estado de origem & $\begin{array}{c}\text { Quantidade de } \\
\text { egressos entrevistados }\end{array}$ \\
\hline Centro Oeste $(\mathrm{CO})$ & Mato Grosso do Sul - MS & 02 \\
\hline Nordeste $(\mathrm{NE})$ & Ceará - CE & 01 \\
\hline Norte $(\mathrm{N})$ & Pará - PA & 03 \\
\hline Sudeste $(\mathrm{SE})$ & Minas Gerais - MG & 02 \\
\hline \multirow{3}{*}{ Sul $(\mathrm{S})$} & Paraná - PR & 03 \\
\hline \multirow{2}{*}{} & Rio Grande do Sul - RS & 08 \\
\cline { 2 - 3 } & TOTAL & $\mathbf{1 9}$ \\
\hline
\end{tabular}

Fonte: Pesquisa de campo (2015).

Para a realização das entrevistas com os egressos, além daquelas realizadas em Porto Alegre (RS), foram necessárias oito viagens de campo, assim distribuídas: uma para Eldorado do Sul (RS); duas para Veranópolis (RS); uma para Governador Valadares (MG); uma para Fortaleza (CE); uma para Belém (PA); uma para Castanhal (PA); e uma para Ponta Porã (MS). Em que pese ter havido três entrevistados do estado do Paraná, este não foi visitado na pesquisa de campo. Esses egressos foram encontrados no Rio Grande do Sul.
Conforme explicado anteriormente, esta pesquisa se deteve aos dados das turmas 05 à 13, todas concluídas e executadas através de convênios entre o INCRA/PRONERA e o ITERRA e o IPECAMPO. As turmas anteriores, além de não terem sido executadas através do PRONERA, tiveram seus documentos destruídos no incêndio ocorrido no local onde funcionava o TAC, município de Braga/RS.

A partir da análise de 493 pastas individuais dos ingressantes no curso TAC nessas nove turmas, foi criado um banco 
de dados com informações básicas dos egressos: nome, sexo, data de nascimento, origem (assentamento, município, estado), bem como a origem dos evadidos/reprovados/transferidos.

A análise deste banco de dados permitiu, através da estatística descritiva, a elaboração de algumas representações gráficas para apresentar o perfil das turmas. Cabe dizer que este material foi enviado para o ITERRA, de forma que o próprio instituto ou demais pesquisadores possam ter acesso.

Apenas os estados do Acre - AC, Amazonas - AM, Amapá - AP e Roraima RR, todos da região Norte, não tiveram nenhum ingresso nessas nove turmas, como pode ser observado no mapa a seguir:

Figura 1: Mapa de alunos ingressos por estado (T5 a T13).

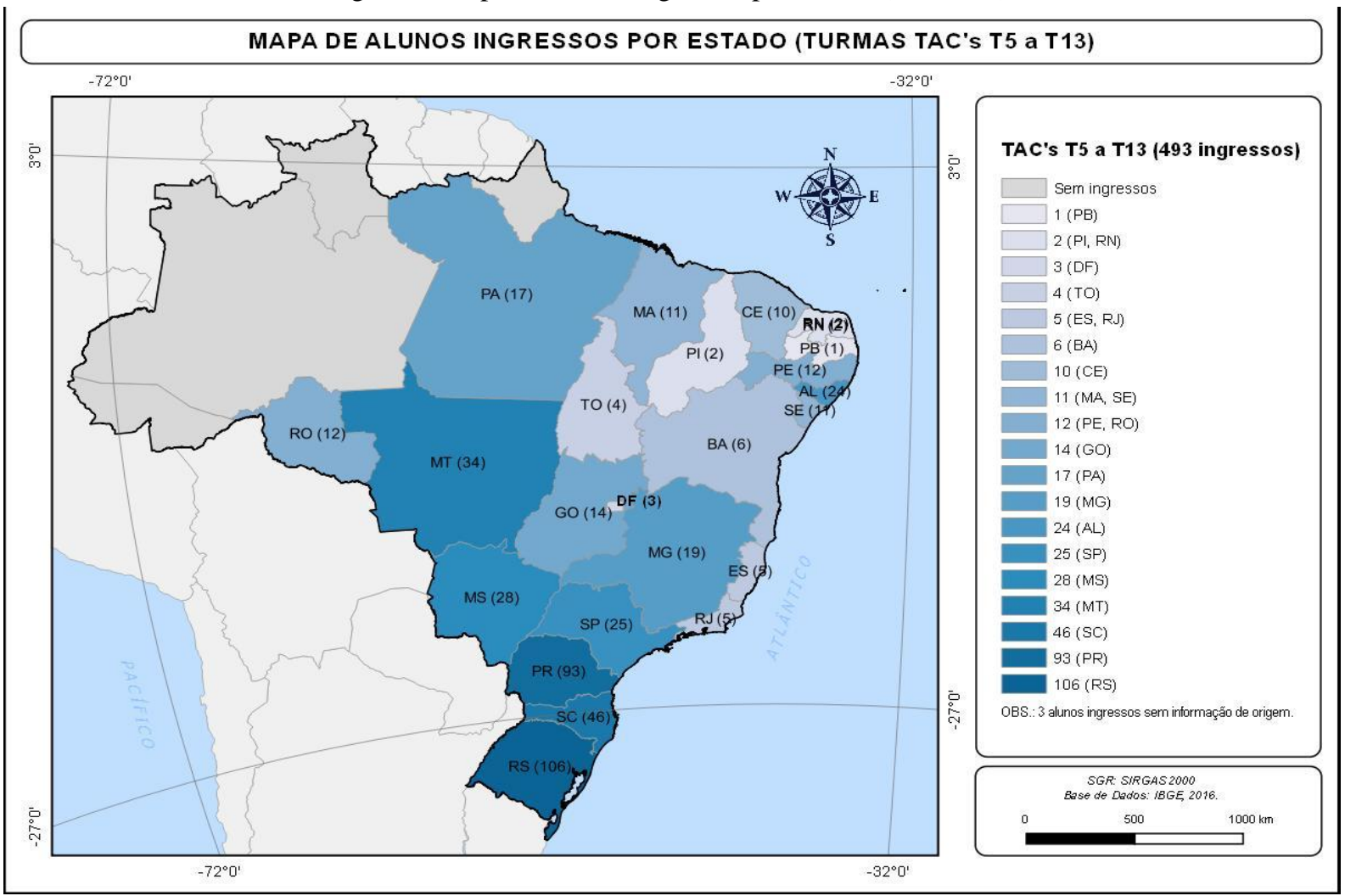

Fonte: Dados da Pesquisa, 2016; IBGE, 2016. Projeto Cartográfico: Antonio Wellington Lira Moreira.

A maior incidência de origem dos ingressos é da região Sul e a menor incidência da região Norte, provavelmente por conta da localização da escola onde ocorre o TAC: Veranópolis/RS. A turma 09 foi a única que não teve representação de todas as regiões, não tendo nenhum ingressante da região Nordeste.

Com base na abordagem seniana este tipo de informações é importante para analisar como um mesmo intitulamento (Curso TAC) tem repercussões 
diferenciadas nas capacitações, dos egressos, neste caso.

Isto ocorre porque, como enfatiza Sen (2008), os seres humanos diferem uns dos outros de muitos modos. Nascem já com uma determinada herança de riqueza (ou pobreza) e responsabilidades. Vivem em ambientes naturais diferentes $\mathrm{e}$ as comunidades ou sociedades às quais pertencem oferecem oportunidades diferentes quanto ao que podem ou não fazer (Sen, 2008).

Mas além dessas diferenças nos ambientes natural e social e nas características externas, também diferimos em nossas características pessoais (p. ex., idades, sexo, aptidões físicas e mentais). E estas são importantes para avaliar a desigualdade (Sen, 2008, p. 51).

Dos 493 ingressantes, 265 concluíram o TAC e 228 evadiram do curso (desistiram, reprovaram ou transferiram-se para outro curso). Analisando os dados, pode-se afirmar que a porcentagem de egressos é proporcional à quantidade de ingressos por região na seguinte ordem decrescente: Sul (S), Centro-Oeste (CO), Nordeste (NE), Sudeste (SE) e Norte (N). Dentre os 22 estados que enviaram estudantes, apenas o estado da Paraíba - PB não teve egresso.

Figura 2: Mapa de alunos egressos por estado (T5 a T13).

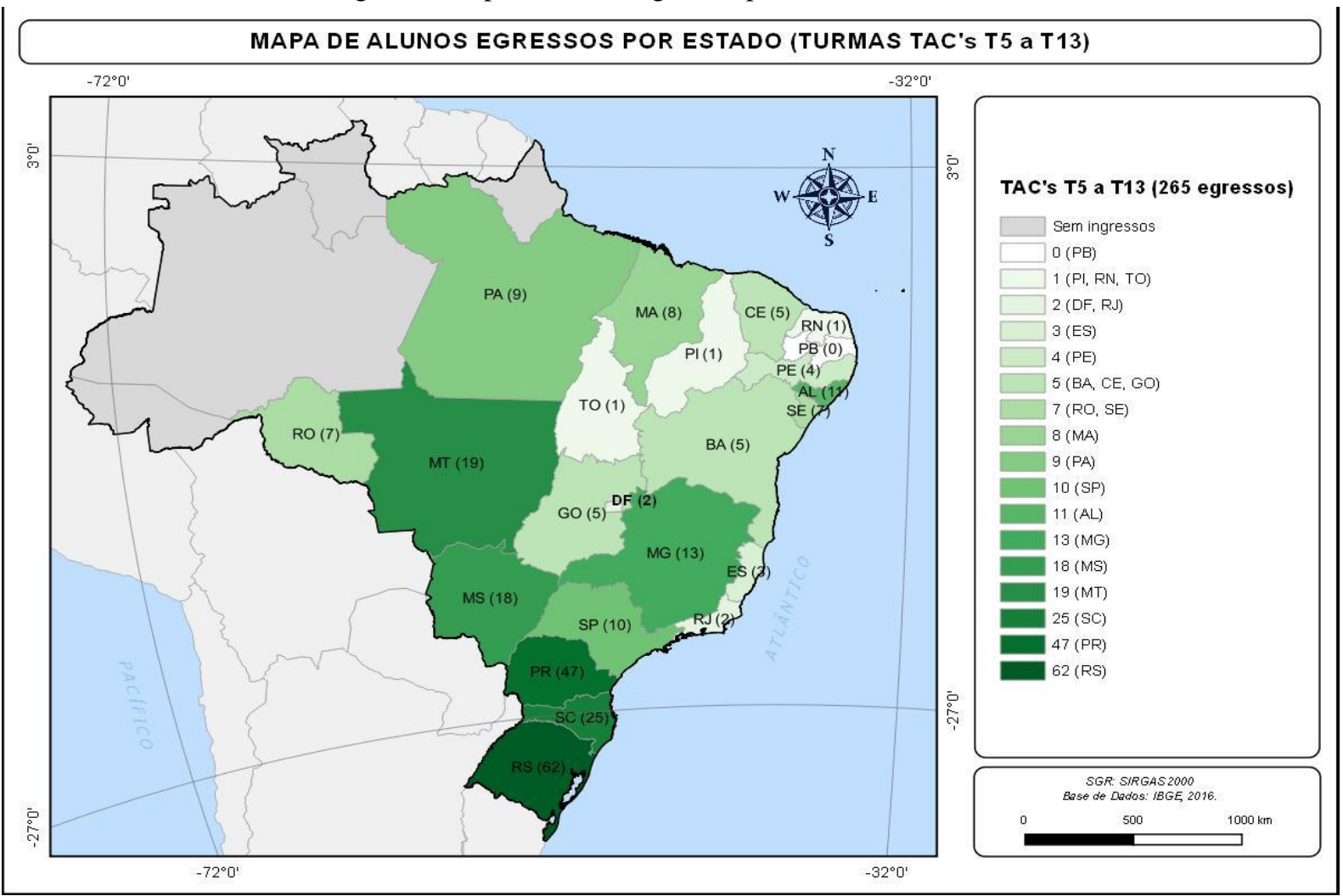

Fonte: Dados da Pesquisa, 2016; IBGE, 2016. Projeto Cartográfico: Antonio Wellington Lira Moreira. 
De 19 entrevistados, 13 não tinham possibilidades de fazer um curso técnico por falta de oferta no município onde residiam. Apenas três teriam a oportunidade de fazer um curso técnico gratuitamente e outros três tinham a oferta de curso na região onde moravam na época que ingressaram no TAC, porém, eram cursos particulares e eles não tinham condições de custear os mesmos e pagar o transporte.

Dos egressos, 14 teriam como primeira escolha outro curso, caso tivesse sido disponibilizado em seu município ou pelo próprio ITERRA. De modo geral, os cursos que teriam escolhidos seriam: Psicologia, Administração, Contabilidade, Agronomia, Economia, Educação Física, Veterinária, Técnico em Agropecuária, qualquer um de formação política ou que trabalhasse diretamente com o povo e qualquer um profissionalizante na área de gestão, mecânica e eletricidade.

Como foi dito anteriormente, na prática, apenas três entrevistados teriam opção de ter realizado algum curso técnico, mesmo em alguma área que não fosse de seu interesse. Analisando este resultado da pesquisa à luz da Abordagem das Capacitações, a limitação de escolhas, em outras palavras, a privação de liberdade, leva o indivíduo a optar por outros caminhos, diferentes de suas "escolhas contrafactuais",iii.

Dentre os entrevistados, cinco já tinham concluído o ensino médio, estando assim distribuídos: um magistério, um auxiliar em contabilidade, um conseguiu o ensino médio pela nota do Exame Nacional do Ensino Médio - ENEM, um ensino médio normal e um cursou duas vezes o ensino médio (Ciências Humanas e Administração). Vale ressaltar que todos os ingressantes no curso TAC participam das aulas do ensino médio no ITERRA, mesmo que já o tenham concluído anteriormente.

Apesar de não ter sido a primeira escolha para a maioria desses egressos, todos responderam que os motivos que os levaram a aceitar o convite de cursar o TAC eram relacionados a dar continuidade aos estudos e contribuir com o MST, assentamentos ou cooperativas dos assentados.

Dentre os entrevistados, três fizeram ou estão fazendo outro curso técnico e 16 (84\%) cursaram algum curso de graduação. Ou seja, $100 \%$ dos entrevistados deram continuidade aos estudos. Dentre eles, dois estão cursando mestrado. Cabe ressaltar que sete dos que cursaram ou estão cursando graduação e um que está cursando mestrado realizaram ou estão realizando estes estudos através do 
PRONERA; cinco dos que estão cursando alguma faculdade particular conseguiram bolsa integral ou parcial pelo Programa Universidade para todos - PROUNI e um está cursando graduação em licenciatura em Educação do Campo pelo Programa Nacional de Educação do Campo PRONACAMPO.

Dentre os 19 entrevistados, 14 estão sendo/ou foram beneficiados por algum programa governamental voltado para a educação. Com isto, arrisca-se afirmar que estes programas podem configurar-se como oportunidades sociais para o desenvolvimento rural, através da expansão das capacitações dessas pessoas.

Aqui vale ressaltar que houve para $100 \%$ dos entrevistados a ampliação das capacitações proporcionada pelo curso TAC. Desta forma, identificou-se que o referido curso pode ser considerado um instrumento de expansão das capacidades dos egressos.

Decorrido mais de uma década após a pesquisa de Menezes Neto (2003), que apontou que $89 \%$ dos estudantes que ainda estavam cursando o TAC queriam ao final do curso trabalhar em cooperativas e apenas $11 \%$ na agricultura, percebeu-se nos resultados que se apresenta neste trabalho que os anseios dos educandos, em certa medida, foram alcançados.
Todos os entrevistados neste trabalho atuaram, depois de formados, em alguma entidade ligada aos assentamentos (no setor produtivo ou na área de educação), permanecendo, a maioria, vinculada a algum desses tipos de entidades. Apenas quatro entrevistados trabalham atualmente fora de área da reforma agrária e em entidades desconectadas da mesma (um motorista concursado de prefeitura municipal, um instalador industrial, uma educadora e também micro empreendedora no setor de alimentos e um articulador e analista de projetos de programa estadual ligado ao desenvolvimento rural).

Alguns entrevistados relataram outro fator limitante na liberdade de escolha de curso técnico em sua região de origem, que seria o ônus de pagar moradia na sede do município para frequentar as aulas durante um a três anos. Aqui, mais uma vez, percebe-se o que Amartya Sen denomina privação de liberdade, um entrave ao desenvolvimento.

Uma questão crucial nesse debate é, portanto, a importância da Pedagogia da Alternância como parte de uma metodologia de ensino que proporcione ao educando do campo possibilidades de estudar, mesmo em locais afastados de seu domicílio.

Esta discussão reforça a importância das políticas de distribuição e 
reconhecimento e do PRONERA como a materialização do direito à educação, dentro deste rol de políticas. Quando a Educação do Campo é questionada pelo senso comum (e até mesmo por acadêmicos) como uma movimentação desnecessária, os depoimentos coletados nas entrevistas aparecem como contraponto, reafirmando sua necessidade.

A pedagogia da alternância é isso, forçava o educando ter uma relação com a origem dele, começar a questionar a origem, começar a fazer parte da origem, porque não adianta se a gente não tem o indutor, a gente não consegue ter essa percepção de você enxergar. $\mathrm{E}$ a pedagogia da alternância era isso, era ter a teoria, voltar e tentar pôr essa teoria aqui, que a gente aprendeu na prática. Aí você retorna com a prática teorizando ela novamente pra ir aperfeiçoando no decorrer do período do curso. Então, isso aí é muito importante, porque você consegue relacionar os fatores e você exercita de fato a tua massa cinzenta que ela tá naquele comodismo. Então, pra mim isso foi determinante (Entrevistado egresso 09).

O curso TAC também proporcionou a esses entrevistados uma melhoria na qualidade de vida, em especial à satisfação pessoal. A maioria teve sua renda aumentada depois de formado, ou passou a adquirir alguma remuneração. A renda, neste trabalho, é considerada, em consonância com a abordagem teórica utilizada, como um meio de buscar mais liberdade em alguma dimensão da vida.
Não é o fim a que se almeja em termos de desenvolvimento. Por isso, investigar se aumentou ou se passou a ter alguma renda significa compreender se houve um aumento na possibilidade de expandir liberdades, tirando o foco das mercadorias.

Além disso, as outras variáveis investigadas sobre os funcionamentos foram observadas: conhecimento técnico; trabalho voluntário; militância em movimento social; cargo em cooperativa; liderança comunitária; elaboração/execução de projetos; aquisição de carga horária técnica para acesso ao PRONAF Jovem; acesso ao ensino superior; contabilidade/gestão da propriedade familiar e atividades socioculturais.

O que se destacou nas entrevistas foi a capacitação na formação humana que a escola proporcionou a todos. Como resultado disso, o curso proporcionou outras variáveis de capacitações e funcionamentos para além dos objetivos de um curso técnico.

Como já apresentado por Caldart (2012) o MST desenvolveu uma pedagogia própria - Pedagogia do Movimento - com base na educação popular e na Pedagogia da Alternância, sendo observada essa peculiaridade nas entrevistas.

... a escola é o Instituto de Educação Josué de Castro, o IEJC, mas ele ... é para além do TAC, porque consegue 
buscar outros espaços educativos, por exemplo, um TAC em qualquer outra escola não é a mesma coisa, como numa escola como o ITERRA. Porque tem algumas atividades que tá na natureza do movimento social, não na natureza do curso. Não tá na grade curricular a noite cultural, não tá na grade a integração, não tá na grade a holística, não tá na grade um monte de trabalho fundamental: trabalhar, pra ajudar na alimentação, tu saber que tu vai fazer o pão, ou tu faz ou tu vai fazer a comida, garantindo que outro tá fazendo o pão... A geleia a gente que produz na agroindústria. Lá é essa divisão técnica, é uma escola pra nós, como é que tu vai aprender no TAC, é uma divisão técnica do trabalho? Tu faz o balancete em cada posto de trabalho que tu faz, se deu errado, isso aí quando tu vai pra sala de aula estudar, fazer um balancete de uma coisa, tu já fez lá, seja no panifício, seja na prestação de serviço, seja na agroindústria, então é uma aula viva, tu aprende TAC e aí tô fazendo o TAC, tô sendo estudante. ... nossa escola é diferente, tu tem que saber que tu tem que lavar prato também, fazer comida, lavar banheiro, porque tu suja, né? Então não é fácil fazer essa pedagogia (Entrevistado egresso 14).

Dessa forma, identificou-se que a formação nesta metodologia de aprendizagem proporcionou possibilidades de adquirir variados tipos de funcionamentos, ou seja, o TAC proporcionou o que Amartya Sen denomina, em outras palavras, as várias coisas que o indivíduo pode ser e fazer.

Ao ser questionado sobre os motivos que levaram à criação do curso TAC, a CONCRAB argumenta que os assentamentos procuravam na sociedade, pessoas para ajudar na administração e associativismo nesses espaços. Porém, os profissionais eram muito voltados ao urbano. Quando surgia alguém mais adequado à realidade rural o custo era muito alto e as cooperativas não tinham como pagar pelos serviços. Então, segundo a CONCRAB, surge o TAC para formar esses técnicos, criando também, um compromisso mais político com as cooperativas, com os assentamentos, para além de conhecer a parte administrativa, de forma a contribuir com o desenvolvimento dos assentamentos, pois a cooperação é mais ampla que o conhecimento de cooperativas.

De certa forma a CONCRAB quando pensou a criação do curso TAC, utilizou-se de um raciocínio semelhante ao preconizado na Abordagem das Capacitações: "O papel fundamental da educação e o de outros meios de expansão das capacidades humanas formam uma conexão sólida no pensamento sobre o desenvolvimento ...” (Dreze \& Sen, 2015, p. 52).

A COCEARGS verifica uma grande presença dos egressos no trabalho do MST como um todo (grupos, associações, cooperativas, agroindústrias). As turmas mais recentes são formadas por pessoas mais novas, com inserção recente no 
acampamento ou assentamento, mas o curso proporciona a aproximação com a dinâmica destes espaços.

Este "banho de realidade" nos estudantes, como explicou a COCEARGS, é possibilitado através da metodologia de alternância do curso. Além dessa proximidade com a realidade, os estudantes relacionam teoria e prática na convivência social em campo, e isso tem os ajudado a ter uma boa qualificação técnica. A entidade prossegue afirmando que em inúmeros lugares, após o estágio, muitos estudantes já recebem convite para contribuir profissionalmente nos assentamentos/cooperativas.

Quando os educandos estão terminando o curso, muitos deles já ficam na cooperativa que fizeram o estágio. Eles somam no controle, no planejamento, acaba criando uma tarefa bem prática e estratégica. Acaba fortalecendo o processo de gestão da cooperativa (Leodimar Ferreira/COCEARGS, 2015).

Esta rápida absorção de maioria desses egressos se dá em boa medida, segundo a COCEARGS, porque eles amadurecem durante o curso e se apropriam de conhecimentos e ferramentas que são úteis nesses empreendimentos de pequeno e médio porte para a introdução de rotinas, procedimentos, ferramentas de controle, etc., que contribuem com a gestão das cooperativas, fazem a diferença.
Identifica-se, a partir da análise da percepção dos representantes das entidades, que o curso TAC tem contribuído não apenas para a ampliação das capacitações dos egressos, individualmente, mas também para os coletivos de assentados (cooperativas, associações, etc.). Portanto, o próprio Amartya Sen aponta: expandir as liberdades não é apenas tornar a vida mais rica, mas tornar seres sociais mais completos, interagindo e influenciando no mundo (Sen, 2010).

\section{Considerações Finais}

Esta pesquisa investigou se o curso Técnico em Cooperativismo - TAC, realizado pelo PRONERA no Rio Grande do Sul, tem contribuído para a expansão das capacitações dos egressos. Ou seja, se o TAC interfere na realização de funcionamentos (estados e ações) e expansão das capacitações das pessoas que o concluíram.

Os termos capacitações e funcionamentos são conceitos da abordagem teórica, desenvolvida por Amartya Kumar Sen, na qual esta pesquisa baseou-se para analisar o campo empírico. No referencial teórico deste trabalho fez-se uma interseção da Abordagem das Capacitações - que mescla princípios 
econômicos e filosóficos - com o tema da Educação do Campo.

De maneira geral, algumas dessas características do curso TAC já eram de conhecimento empírico para quem trabalha no cotidiano do IEJC/ITERRA, porém, este trabalho embasa com os dados coletados a partir de uma análise da estatística descritiva e acrescenta algumas informações que a observação empírica não permitira apreender.

Os dados consolidados ilustram e sistematizam, através de método científico, os relatos da experiência dos educadores do IEJC/ITERRA. Além disso, o resultado desta etapa da pesquisa é um complemento às publicações, principalmente livros/cadernos do ITERRA, que versam sobre a temática, mas tratam o perfil da escola como um todo, não apresentando dados quantitativos específicos sobre o TAC.

Todos os egressos tinham um intitulamento em comum: o acesso à escolarização (Ensino médio e/ou ensino técnico) através do Curso Técnico em Cooperativismo. Este foi o ponto de partida para averiguar as outras variáveis.

As diferenças encontradas nos assentamentos visitados e os relatos que apresentaram realidades totalmente diversas da região Sul (onde se concentram os educandos) foram muito interessantes.
As entrevistas na região Norte, por exemplo, trouxeram dificuldades anteriores aos problemas que as cooperativas do Sul possuem. Questões como violência e falta de políticas públicas, como assistência técnica, mostraram que dificilmente as realizações dos egressos serão as mesmas daqueles que permaneceram no Sul. Não é de se admirar que a região Norte tenha apresentado a maior taxa de evasão.

Apesar de ter sido identificado pelos próprios entrevistados o empoderamento feminino através do curso TAC, caberia à escola traçar novas estratégias para a equidade entre homens e mulheres na composição das turmas. Além disso, em relação à possibilidade de criação de curso no Nordeste, a maior incidência de evasão se dá no Norte, cabendo também uma discussão acerca da possibilidade de ampliar o curso para atender a realidade específica dessa região.

As entrevistas realizadas na região Sudeste também revelaram a escassez das políticas públicas nos assentamentos. Este problema aliado à falta de cooperativas na região visitada ocasionou, por exemplo, a falta do funcionamento "emprego remunerado" para um egresso entrevistado.

Durante a pesquisa de campo, foi observado que a pesquisa foi bem recepcionada tanto pelos entrevistados, como pelas lideranças locais nos 
assentamentos. A dificuldade de deslocamento não foi grande para chegar aos assentamentos porque a pesquisa contou com diversas formas de contribuição (informações, hospedagem, caronas, acompanhantes locais, etc.) que o próprio MST disponibilizou para a realização das entrevistas.

A maioria dos estudos sobre o TAC ocorreu no próprio ITERRA, mas a expansão territorial do campo de investigação que este trabalho realizou foi fundamental para complementar a análise teórica sobre a realidade encontrada. Avalia-se que a metodologia utilizada foi adequada para o referencial teórico escolhido e vice-versa.

$\mathrm{Na}$ análise das entrevistas com os egressos, foram identificadas as variáveis teóricas que orientaram a pesquisa de campo. Contudo, a realidade se apresentou ainda mais diversa, fornecendo outras variáveis que o trabalho não foi capaz de elaborar inicialmente, apenas com o referencial teórico, pois foi o próprio empírico que revelou essa diversidade.

Para os egressos, de forma geral, o processo formativo do curso TAC tem contribuído na expansão da liberdade deles. Isto porque, ao adquirir capacidade para realizar funcionamento, não somente como consequência da titulação de ensino médio e/ou técnico, mas também pelo processo educativo experenciado no ITERRA, esses egressos puderam realizar atividades diversas, conquistaram espaços e mudaram o seu modo de ser. Eles tiveram o leque de escolhas ampliado, complementado pelas oportunidades advindas de programas e políticas públicas (ENEM, PROUNI, PRONACAMPO, PRONERA), que complementaram a capacidade de realizações adquirida.

Vale dizer que essas entidades são coordenadoras do curso em nível nacional (CONCRAB) e estadual (COCEARGS). Apesar disso, as mesmas não possuem os dados de quantos egressos contribuem nas cooperativas dos assentamentos, nem mesmo apenas no RS.

Ambas as entidades conseguem definir o que consideram importante para o desenvolvimento rural e a forma como o TAC como um todo vem contribuindo para o desenvolvimento dos assentamentos. Este resultado foi além do que se pretendia: a pesquisa de campo conseguiu investigar, além da COCEARGS, o ponto de vista da CONCRAB ${ }^{\text {iv }}$.

Estando ou não diretamente nos assentamentos, essas entidades avaliam que os egressos, vinculados a movimentos sociais da classe trabalhadora e atuando nas cooperativas (ou outras organizações) de assentamentos, estão contribuindo para o desenvolvimento desses, diante da 
contribuição política e técnica nessas organizações, na luta por conquistas de direitos aos assentamentos, ou na elaboração ou execução de projetos técnicos/políticos/produtivos que visem contribuir para o desenvolvimento das áreas de assentamento.

A pesquisa conclui, portanto, que o curso TAC tem contribuído para a expansão das capacitações dos egressos e não somente aquelas previstas inicialmente, mas para várias outras, identificadas durante as entrevistas. Estas capacitações e funcionamentos observados devem-se não ao diploma fornecido pela instituição de ensino, mas pela experiência pedagógica da escola como um todo.

Por fim, como o trabalho delimitou o público aos egressos, sendo que a maioria está vinculada a alguma atividade ligada ao MST, a maior parte da análise do processo educativo e seus resultados foi bastante positiva. Novos estudos poderiam abordar o universo dos evadidos do curso, contribuindo assim para ampliar a discussão desta pesquisa.

\section{Referências}

Arroyo, M. G. (2010). Políticas Educacionais e Desigualdades: à procura de novos significados. Educação \& Sociedade, 31(113), 1381-1416. DOI: http://dx.doi.org/10.1590/S0101$\underline{73302010000400017}$
Caldart, R. S. (2012). Pedagogia do Movimento Sem Terra. São Paulo, SP: Expressão Popular.

Castro, V. M. V., \& Melo, C. C. (2014). Programa Nacional de Educação na Reforma Agrária (PRONERA): uma proposta de avaliação em profundidade. Avaliação de Políticas Públicas, 2(14), 96107.

Cerioli, P. R. (1997). Educação para a cooperação: experiência do curso técnico em administração de cooperativas do MST. (Monografia de Especialização), Universidade do Vale do Rio dos Sinos, Rio Grande do Sul.

Christoffoli, P. I. (2007). Elementos para um balanço do Curso Técnico em Administração de Cooperativa. Cadernos do ITERRA, 7(13), 71-128.

Dreze, J., \& Sen, A. (2015). Glória Incerta: a Índia e suas contradições. São Paulo, SP: Companhia das Letras.

Fernandes, B. M., \& Molina, M. C. (2004). O campo da educação do campo. In Molina, M. C., \& Azevedo de Jesus, S. M. S. (Orgs.). Por uma Educação do Campo: contribuições para a construção de um projeto de Educação do Campo. (pp. 5389). Brasília, DF: Articulação Nacional Por uma Educação do Campo.

Garcia, R. (2008). Consolidação das políticas educacionais do campo. Tangará da Serra, MT: Gráfica e Editora Sanches LTDA.

Kuhn, D. D. (2004). O microcrédito com instrumento de desenvolvimento rural no município de Constantina/RS: a abordagem seniana de desenvolvimento. (Dissertação de Mestrado). Universidade Federal do Rio Grande do Sul, Rio Grande do Sul.

Mattos, E. J. (2006). Pobreza rural no 
Brasil: um enfoque comparativo entre a abordagem monetária e a abordagem das capacitações. (Dissertação de Mestrado). Universidade Federal do Rio Grande do Sul, Rio Grande do Sul.

Menezes Neto, A. J. (2003). Além da Terra: cooperativismo e trabalho na educação do MST. Rio de Janeiro, RJ: Quarter.

Molina, M. C. (2008). A Constitucionalidade e a Justiciabilidade do Direito à Educação dos Povos do Campo. In Santos, C. A. (Org.). Educação do Campo: campo-políticas públicas educação (pp. 19-32). Brasília, DF: INCRA/MDA.

Picolotto, V. C. (2010). Educação como expansão das capacitações: Uma breve análise dos resultados da Prova Brasil. In Anais da III Conferência Latino Americana e Caribenha sobre Abordagem das Capacitações e Desenvolvimento Humano (pp. 1-28). Porto Alegre, RS.

Santalucia, M., \& Hegedus, P. (2005). Cooperativismo e Assentamento Rural na percepção do uso coletivo e individual da terra mediante metodologia Q: o caso de Charqueadas. Revista Extensão Rural, 12, 97-128.

Sen, A. (2011). A ideia de Justiça. São Paulo, SP: Companhia das Letras.

(2010). Desenvolvimento como Liberdade. São Paulo, SP: Companhia das Letras.

\section{(2008). Desigualdade}

Reexaminada. Rio de Janeiro: São Paulo, SP: Record.

Silva, M. S. (2006). Da raiz à flor: produção pedagógica dos movimentos sociais e a escola do campo. In Molina, M. C. (Org.) Educação do Campo e Pesquisa
- Questões para reflexão (pp. 60-93). Brasília, DF: MDA.

\footnotetext{
${ }^{\text {i }}$ São caracterizadas por populações e comunidades que têm seus modos de vida, produção e reprodução social relacionados predominantemente com a terra, água e florestas. Neste contexto estão os camponeses, agricultores familiares, trabalhadores rurais assentados ou acampados, comunidades tradicionais, etc.

ii Política compensatória é uma resposta à reivindicação para que se repare um dano ocorrido no passado em relação aos membros de determinado grupo minoritário. Neste trabalho o surgimento do Pronera é assim considerado pois repara em parte os efeitos históricos da educação rural precária.

iii Escolha contrafactual é o que alguém teria escolhido se tivesse escolha (Sen, 2008).

iv Além dos dois representantes da COCEARGS entrevistados, durante a pesquisa de campo houve a oportunidade de encontrar no ITERRA um representante da CONCRAB, que se disponibilizou a conceder entrevista.
}

Recebido em: 20/11/2017 Aprovado em: 17/01/2018 Publicado em: 26/02/2018

Como citar este artigo / How to cite this article / Como citar este artículo:

APA:

Melo, C. C., Waquil, P. D. (2018). O Curso Técnico em Cooperativismo realizado pelo PRONERA: uma análise baseada na Abordagem das Capacitações. Rev. Bras. Educ. Camp., 3(1), 126-152.

ABNT:

MELO, C. C., WAQUIL, P. D. O Curso Técnico em Cooperativismo realizado pelo PRONERA: uma análise baseada na Abordagem das Capacitações. Rev. Bras. Educ. Camp., Tocantinópolis, v. 3, n. 1, p. 126-152, 2018. 
Melo, C. C., Waquil, P. D. (2018). O Curso Técnico em Cooperativismo realizado pelo PRONERA...

\section{ORCID}

Conceição Coutinho Melo

(iD) http://orcid.org/0000-0001-7758-3345

Paulo Dabdab Waquil

(iD http://orcid.org/0000-0002-9430-7040

Os autores Conceição Coutinho Melo e Paulo Dabdab Waquil declaram serem responsáveis pela elaboração do artigo, sendo que a primeira autora participou da elaboração do projeto, coleta de dados, análise e interpretação dos dados, escrita e revisão do conteúdo do manuscrito e o segundo autor orientou todas as etapas do trabalho, sendo ambos responsáveis pela aprovação da versão final a ser publicada. 